Article

\title{
Effects of Preferential Incorporation of Carboxylic Acids on the Crystal Growth and Physicochemical Properties of Aragonite
}

\author{
Seon Yong Lee, Uijin Jo ${ }^{\dagger}$, Bongsu Chang $($ ib and Young Jae Lee *(D) \\ Department of Earth and Environmental Sciences, Korea University, 145 Anam-ro, Seongbuk-gu, \\ Seoul 02841, Korea; reddevels86@korea.ac.kr (S.Y.L.); uijin.jo@erm.com (U.J.); bschang@korea.ac.kr (B.C.) \\ * Correspondence: youngjlee@korea.ac.kr; Tel.: +82-2-3290-3181; Fax: +82-2-3290-3189 \\ † Present address: Environmental Resources Management (ERM), Samhwa Tower (12F), 16 euljiro-5gil, Jung-gu, \\ Seoul 04539, Korea.
}

Received: 29 September 2020; Accepted: 21 October 2020; Published: 22 October 2020

check for updates

\begin{abstract}
The preferential incorporation of carboxylic acids into aragonite and its effects on the crystal growth and physicochemical properties of aragonite were systematically investigated using a seeded co-precipitation system with different carboxylic acids (citric, malic, acetic, glutamic, and phthalic). Aragonite synthesized in the presence of citric and malic acids showed a remarkable decrease in the crystallinity and size of crystallite, and the retardation of crystal growth distinctively changed the crystal morphology. The contents of citric acid and malic acid in the aragonite samples were $0.65 \mathrm{wt} \%$ and $0.19 \mathrm{wt} \%$, respectively, revealing that the changes in the physicochemical properties of aragonite were due to the preferential incorporation of such carboxylic acids. Speciation modeling further confirmed that citric acid with three carboxyl groups dominantly existed as a metal-ligand, (Ca-citrate) $)^{-}$, which could have a strong affinity toward the partially positively charged surface of aragonite. This indicates why citric acid was most favorably incorporated among other carboxylic acids. Our results demonstrate that the number of carboxyl functional groups strongly affects the preferential incorporation of carboxylic acids into aragonite; however, it could be suppressed by the presence of other functional groups or the structural complexity of organic molecules.
\end{abstract}

Keywords: aragonite; carboxylic acids; preferential incorporation; crystal growth; physicochemical properties

\section{Introduction}

Aragonite occurs as calcium carbonate $\left(\mathrm{CaCO}_{3}\right)$, which has three different anhydrous crystalline polymorphs: the thermodynamically most stable rhombohedral calcite, the metastable orthorhombic aragonite, and the hexagonal vaterite [1,2].

The crystal lattice of aragonite differs from that of calcite, and it comprises different shapes such as needles or prismatic-like crystals with high aspect ratios [3-6]. As a result of the structural properties of aragonite crystals, they can be used as raw materials in various industrial areas: rubber, plastic, textile, filler for paint, pigment for papers [7-9], and additives to improve the brightness and transparency of ceramics and pharmaceuticals [10]. In these various industrial fields, the crystal morphology and size distributions of aragonite are considered important factors for enhancing industrial applications [11]. For this reason, precise control of the crystal properties of aragonite, such as the size, shape, and specific surface area, is required for many technological applications [4,12].

Several previous studies have shown that the physicochemical properties of aragonite crystals can be easily controlled by varying the synthetic conditions (e.g., temperature, pressure, aging time, 
concentrations of $\mathrm{Ca}^{2+}$ and $\mathrm{CO}_{3}{ }^{2-}$, carbonization degree, diffusion, and presence of organic substances or coexisting ions) [4,12-20]. Among them, the presence of organic ligands can lead to the formation of biogenic calcium carbonates through biomineralization [19-21]. The resulting aragonite has complex structures generally not found in inorganic crystals. For example, compared to that of aragonite formed inorganically, an aragonite shell containing organic ligands has a work of fracture of over 3000 times [22]. Moreover, aragonitic nacre (with 5\% organic material) shows remarkable mechanical properties [23,24]. For these reasons, the biomimetic design of calcium carbonates has been an interesting subject and has intrigued many material scientists to date.

Until recently, many studies have focused on the synthesis of calcium carbonates in the presence of organic acids, which have been reported to affect the crystal morphology, retard the crystal nucleation and growth, and control the polymorphism of calcium carbonates [25-32]. In particular, the previous studies using calcite confirmed that this organic effect was concentrated in certain organic acids containing carboxylic functional groups [25-27]. They suggested that the inhibition of calcite growth was due to the adsorption of carboxylic acids onto the calcite surface, and the inhibitory capacity of the organic ligands depended on the number of carboxyl groups in the molecule. In addition, Reddy et al. (2001) [25], who studied calcite growth in the presence of carboxylic acids with different structures (linear and cyclic), showed that cyclic polycarboxylic acids were much more efficient for the inhibition of calcite growth. This means that in addition to the number of carboxyl groups, the structural conformation (aliphatic chain vs. aromatic ring) of organic molecules should be considered when controlling the properties of calcium carbonates such as aragonite.

Considering the similarity of calcite and aragonite, aragonite is also expected to be significantly affected by carboxylic acids. In addition, as confirmed in the studies on calcite, the effects of carboxylic acids on the physicochemical properties of aragonite crystals could be different depending on the type of the organic functional group (e.g., carboxyl group $-\mathrm{COO}(\mathrm{H})$ or amino group $-\mathrm{NH}_{2}$ ) or structural conformation of organic molecules (e.g., chain or aromatic hydrocarbon structures). However, research on the incorporation of organics into aragonite has been mostly conducted based on the biologically originated aragonite, and the investigation of organic incorporation mechanism through the systematic synthesis of aragonite under controlled conditions has not been reported yet. Compared to calcite, for these reasons, the effects of the structural characteristics of organic acids containing carboxyl functional groups on crystal growth and the physicochemical properties of aragonite crystals have not been fully understood.

Therefore, we designed a seeded co-precipitation system for growth of aragonite in the presence of different types of carboxylic acids considering the number of carboxyl groups, structure, and arrangement of functional groups to investigate the effects of carboxylic acids on the crystal properties of aragonite. Furthermore, we performed speciation modeling to explain the possible mechanism(s) of confirmed preferential incorporation of certain carboxylic acids into aragonite, because the form in which the organic acid exists (i.e., metal-organic complexes or organic species) is relevant for the incorporation into carbonate mineral during crystallization [33,34].

This is the first systematic investigation using a seeded co-precipitation method on (1) the incorporation of carboxylic acids into synthetic aragonite and (2) the subsequent changes in the crystal properties of the co-precipitated aragonite.

\section{Materials and Methods}

\subsection{Materials}

All reagent grade chemicals were purchased from Sigma-Aldrich Korea (Seoul, Korea) and used in this study without further purification. Calcium chloride dihydrate $\left(\mathrm{CaCl}_{2} \cdot 2 \mathrm{H}_{2} \mathrm{O}\right)$, sodium bicarbonate $\left(\mathrm{NaHCO}_{3}\right)$, sodium carbonate $\left(\mathrm{Na}_{2} \mathrm{CO}_{3}\right)$, sodium chloride $(\mathrm{NaCl})$, magnesium chloride hexahydrate $\left(\mathrm{MgCl}_{2} \cdot 6 \mathrm{H}_{2} \mathrm{O}\right)$, and six different types of carboxylic acids (citric, malic, acetic, glutamic, and phthalic) were used for the synthesis of aragonite seed and aragonite co-precipitated with carboxylic acids. 
Analytical grade hydrochloric acid $(\mathrm{HCl}, 37 \%)$ and sodium hydroxide solution $(\mathrm{NaOH}, 50 \%)$ were also used to adjust the solution $\mathrm{pH}$. DI (de-ionized) water with a resistance of $18.2 \mathrm{~m} \Omega$ was used in all experiments.

The carboxylic acids used in this study were classified into three cases, and their characteristics are shown in Table 1. Case 1 was composed of acetic acid, malic acid, and citric acid, which have different numbers of carboxyl functional groups $(1,2$, and 3 of $\mathrm{COO}(\mathrm{H})$, respectively); this was used to confirm the effects of the number of carboxyl functional groups on the growth and crystal properties of aragonite. Case 2 was composed of malic acid, glutamic acid, and phthalic acid, which have two carboxyl functional groups and other different functional groups (i.e., hydroxyl or amino groups) and organic structures (i.e., carbon chain or cyclic structure) to confirm the effects of various functional groups as well as the structure and weight of different organic molecules on the growth and crystal properties of aragonite.

Table 1. Characteristics of the organic acids used in this study.

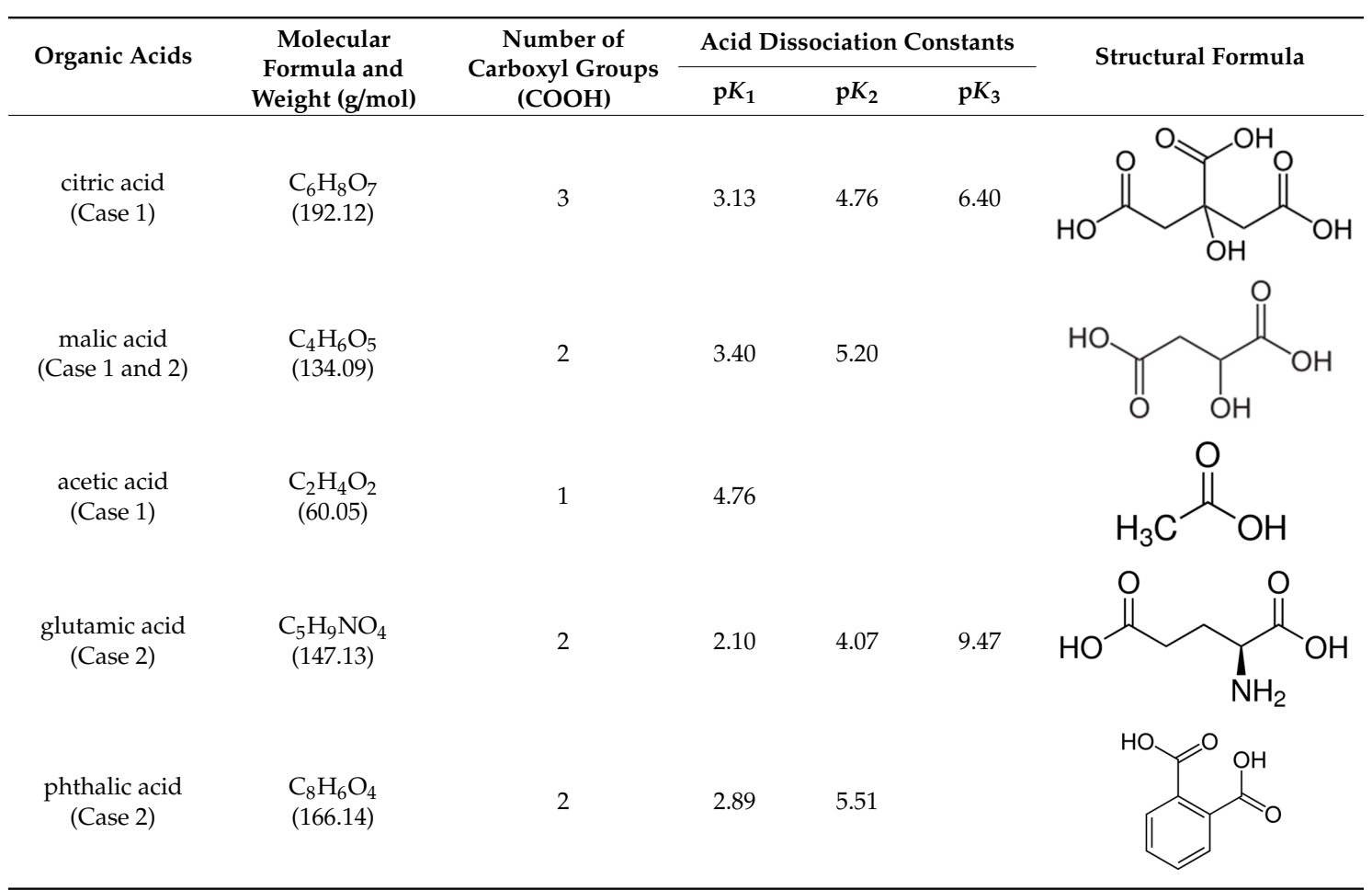

Note: Information on these organic acids was provided by the National Center for Biotechnology Information [35].

\subsection{Synthesis of Organic Co-Precipitated Aragonite}

\subsubsection{Aragonite Seed Preparation}

Before the co-precipitation experiment to obtain the organic co-precipitated aragonite, size-controlled pure aragonite to be used as an aragonite seed was prepared through a constant-addition method [33]. The synthetic method is briefly described as follows. First, $0.007 \mathrm{M} \mathrm{NaHCO}_{3}, 0.1 \mathrm{M}$ $\mathrm{NaCl}$, and $0.05 \mathrm{M} \mathrm{MgCl}_{2} \cdot 6 \mathrm{H}_{2} \mathrm{O}$ were dissolved in $3.5 \mathrm{~L}$ of DI water with vigorous stirring using a Teflon-coated magnetic bar. Thereafter, $0.007 \mathrm{M} \mathrm{CaCl}_{2} \cdot 2 \mathrm{H}_{2} \mathrm{O}$ solution was injected into the bicarbonate solution for $1-6 \mathrm{~h}$ at a constant rate $(0.1 \mathrm{~mL} / \mathrm{min})$ using a multi-racks syringe pump to saturate the reaction solution with respect to aragonite. The solution temperature was maintained at $25 \pm 0.1^{\circ} \mathrm{C}$ using a hotplate magnetic stirrer with a temperature sensor (C-MAG HS7/ETS-D5, IKA, Staufen, Germany) during all experiments. Then, the mixture of solution and precipitates was separated using a cellulose nitrate membrane with a $0.45-\mu \mathrm{m}$ pore size, and the filtered solid sample was dried in an oven at $60^{\circ} \mathrm{C}$ for $12 \mathrm{~h}$ and stored in a desiccator for characterization and co-precipitation experiments. 


\subsubsection{Co-Precipitation Experiment}

Different concentrations of $0.1,0.5$, and $1.0 \mathrm{mM}$ of each carboxylic acid were added to the individual reaction vessel containing $700 \mathrm{~mL}$ of initial growth solution that contained $0.007 \mathrm{M}$ $\mathrm{CaCl}_{2} \cdot 2 \mathrm{H}_{2} \mathrm{O}, 0.007 \mathrm{M} \mathrm{NaHCO}_{3}, 0.1 \mathrm{M} \mathrm{NaCl}, 0.05 \mathrm{M} \mathrm{MgCl}_{2} \cdot 6 \mathrm{H}_{2} \mathrm{O}$, and $0.1 \mathrm{~g}$ of the pre-synthesized pure aragonite seed. The saturation index (SI) of this initial growth solution was 1.44, indicating that the solution is supersaturated with respect to aragonite (Supplementary Materials Figure S1) [33]. Then, $60 \mathrm{~mL}$ of Ca solution $\left(0.3 \mathrm{M} \mathrm{CaCl}_{2} \cdot 2 \mathrm{H}_{2} \mathrm{O}+0.1 \mathrm{M} \mathrm{NaCl}\right.$ with $0.1-1.0 \mathrm{mM}$ carboxylic acid) and $60 \mathrm{~mL}$ of $\mathrm{CO}_{3}$ solution $\left(0.3 \mathrm{M} \mathrm{Na}_{2} \mathrm{CO}_{3}+0.1 \mathrm{M} \mathrm{NaCl}\right)$ were injected to the growth solution using a dual syringe pump (Legato 200/78-8300, Sercrim Labtech, Seoul, Korea) at a constant rate of $0.1 \mathrm{~mL} / \mathrm{min}$ for $10 \mathrm{~h}$. Throughout the experiment, dust-free clean air, produced by passing air through a glass tube containing DI water, was injected into the growth solution through a micro-bubbler to maintain equilibrium with $\mathrm{CO}_{2}(\mathrm{~g})$ in air during the process. As a result, the $\mathrm{pH}$ of the mixed solution was kept at approximately 8.3 throughout the co-precipitation experiment, even in the different carboxylic acids (see Figure S2; the $\mathrm{pH}$ is slightly higher than 8.3 in the presence of citric and malic acids, but the difference is not significant). The temperature of the mixed solution was maintained at $25 \pm 0.1{ }^{\circ} \mathrm{C}$ with stirring at $200 \mathrm{rpm}$. At the end of the experiment, precipitates were filtered using a $0.45-\mu \mathrm{m}$ membrane filter, thoroughly rinsed several times with DI water adjusted to $\mathrm{pH} 8.3$, and dried at $60^{\circ} \mathrm{C}$ for $12 \mathrm{~h}$ for characterization. The organic co-precipitated aragonite samples synthesized in the presence of citric, malic, acetic, glutamic, and phthalic acids were labeled citric-arag, malic-arag, acetic-arag, glutamic-arag, and phthalic-arag, respectively. The sample to compare the effect of the presence of carboxylic acids was synthesized under the same condition without organic acid and labeled as the control.

\subsection{Characterization}

The mineral phase and crystallinity of the synthesized aragonite seed samples were confirmed by powder X-ray diffraction (PXRD, SmartLab, Rigaku, Tokyo, Japan) using $\mathrm{Cu}-\mathrm{K} \alpha$ at $40 \mathrm{kV}$ and $100 \mathrm{~mA}$ with a $0.01^{\circ}$ step size and a $0.5^{\circ} \mathrm{min}$ scan rate. To refine the structural parameters of the co-precipitated aragonite samples synthesized in the presence of different types of organic acids with $0.1 \mathrm{~g}$ of aragonite seed, additional PXRD analysis was performed on a Bruker D8 Advance diffractometer (D8 Advance, Bruker, Billerica, MA, USA) equipped with a LynxEye ${ }^{\circledR}$ XE-T 1D detector with 192 channels. The $2 \theta$ angle covered from 5 to $70^{\circ}$, with a scanning angle step size of $0.015^{\circ}$ and a time step of 0.250 sec. The powder sample was placed on an XRD sample holder using the side-loading method to minimize the preferential orientation of certain crystal planes of the sample by top pressure. Furthermore, Rietveld refinement was performed on the XRD data using the program BGMN with the help of the graphical user interface software Profex-4.2.1 [36,37]. The experimental XRD profile was modeled with a Lorentzian function under the conditions of anisotropic crystallite size as well as anisotropic micro strain. Crystallite size was determined from anisotropic peak broadening of the (111) reflection using the internal algorithms, which were embedded in the program BGMN. The quality of refinements was evaluated with the goodness of fit (see Table 2), which was below 1.3, confirming the reliability of the computed models.

The crystal morphology of the samples was confirmed using field emission scanning electron microscopy (FE-SEM, 250FEG, FEI, Hillsboro, OR, USA). SEM analysis of each sample coated with platinum was conducted at an accelerating voltage of $15 \mathrm{kV}$. High-resolution transmission electron microscopy (HR-TEM, Tecnai 20, FEI, Hillsboro, OR, USA) and selected area electron diffraction (SAED) pattern analyses were conducted on a single aragonite crystal sample at an accelerating voltage of $200 \mathrm{kV}$ to obtain high-resolution images and reciprocal lattice patterns. The average particle size and distribution of aragonite seeds were measured by a particle size distribution analyzer (PSD, ELSZ-1000, Otsuka Electronics Korea, Seongnam-si, Korea) using a mixed solution of $0.01 \mathrm{~g}$ solid powder dispersed in $5 \mathrm{~mL}$ of ethanol solvent. The possible co-precipitation of carboxylic acids with aragonite was investigated by high-performance liquid chromatography (HPLC), Fourier transform-infrared (FT-IR), 
and thermogravimetric and differential scanning calorimetry (TG-DSC) analyses of the precipitates. The contents of the incorporated carboxylic acids in the co-precipitated aragonite samples were measured by HPLC (1200 series, Agilent Technologies, Waldbronn, Germany) at the Korea Institute of Science and Technology (KIST) [34]. Briefly, each organic co-precipitated solid sample was treated with $1 \mathrm{M}$ of $\mathrm{HCl}$ to dissolve the solid sample and ionize the organic acid contained in the solid into liquid phase. The measured organic concentration in solution was converted to mass unit and expressed as the weight percent ( $\mathrm{wt} \%$ ) based on the used mass of the solid sample. The FT-IR spectra of the samples were obtained in an absorbance mode with a range of $4000-400 \mathrm{~cm}^{-1}$ on an ATR-FTIR spectrometer (Agilent Technologies, Inc., Santa Clara, CA, USA). TG-DSC analysis was performed using a thermal gravimetric analyzer (SDT Q600, TA Instruments, New Castle, DE, USA) under air conditions at a heating rate of $5^{\circ} \mathrm{C} / \mathrm{min}$. The speciation of organic acids in each experimental condition was calculated using the geochemical modeling software PHREEQC (version 2.18, U.S. Geological Survey, Reston, VA, USA) with the database minteq.v4.dat containing various organic species data [38].

\section{Results and Discussion}

\subsection{Characterization of Aragonite Seeds}

The crystal properties of aragonite samples prepared with different aging times were analyzed to determine the optimum conditions for the synthesis of aragonite seeds of suitable size. It is important to use a small-sized seed to confirm the effects of carboxylic acids on the growth of aragonite crystals because the incorporation of carboxylic acids into aragonite can affect the surface structure, morphology, and ultimately the crystallinity of aragonite crystals during co-precipitation. Therefore, considering the known growth mechanism of aragonite with respect to aging time [6,8], aragonite seeds were synthesized at different reaction times $(1,2$, and $6 \mathrm{~h})$ under our experimental conditions.

Figure 1 shows that the positions of the XRD peaks of all samples were consistent with those of an aragonite reference (JCPDS No. 01-078-4339) without a secondary phase, which indicates that pure aragonite was formed. However, the XRD peak intensity related to the crystallinity of the sample changed distinctively with reaction time. The increased XRD peak intensity with reaction time indicates that the crystallinity of the synthesized aragonite was increased. When the epitaxial-oriented overgrowth of a single crystal is satisfied, the regularity of the crystal lattice structure increases. Therefore, considering the constant addition of the Ca solution at a slow rate into the growth solution supersaturated with respect to aragonite, this increase in the crystallinity of aragonite with reaction time could be explained by an increase in crystal size through crystal growth [39]. 


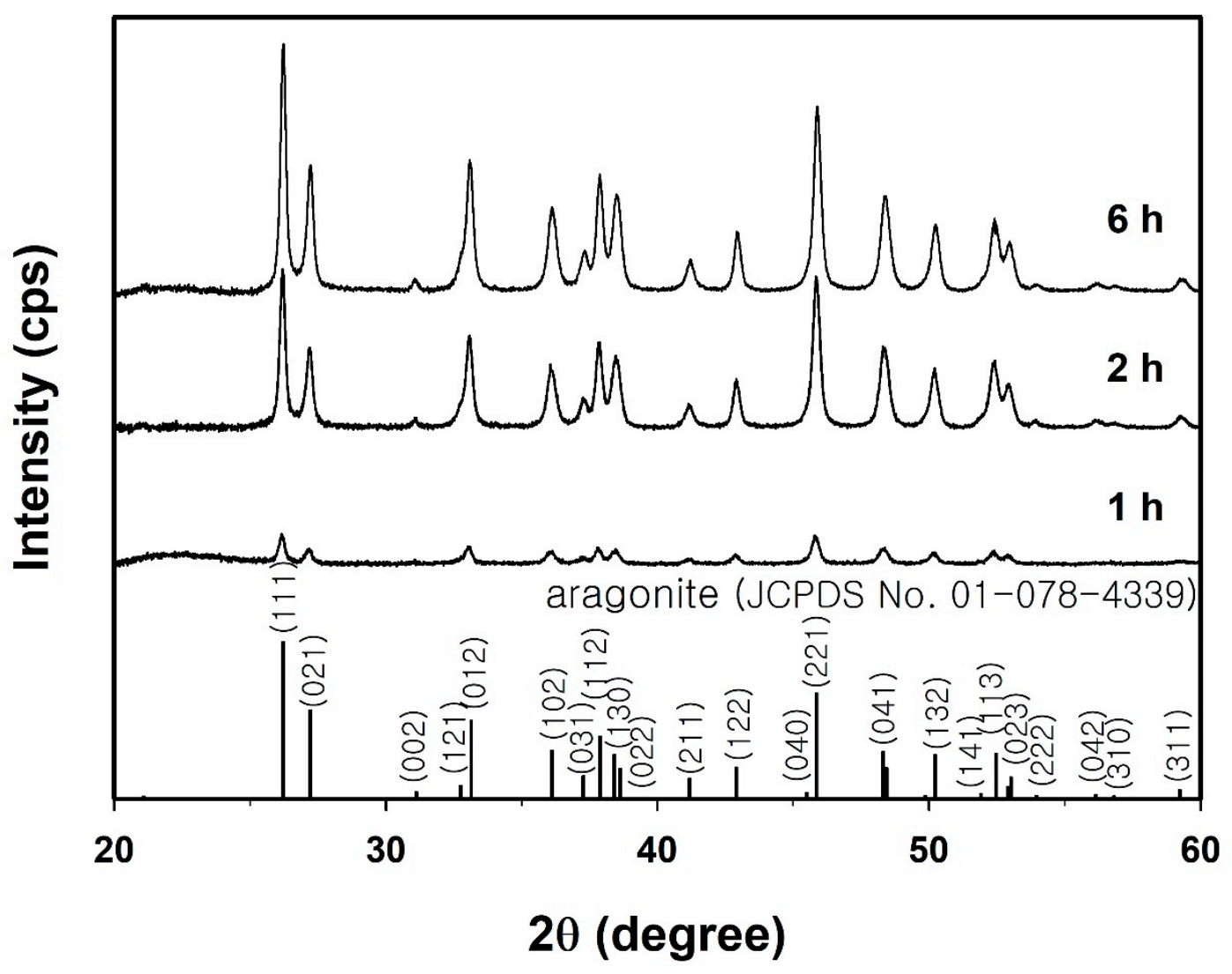

Figure 1. XRD patterns of samples synthesized with different aging times of 1,2 , and $6 \mathrm{~h}$ in the absence of organic acids.

The crystal growth is also shown in the SEM images for different samples synthesized at different reaction times (1 to $6 \mathrm{~h}$ ) (Figure 2). The samples showed similar dandelion flower-like shaped particles composed of many needle-like aragonite crystals. Lee et al. (2015) reported a similar spherical growth mechanism in the previous study on the effects of aging time on strontianite $\left(\mathrm{SrCO}_{3}\right)$, which has an orthorhombic crystal system similar to aragonite. Such spherical growth behavior by the aggregation of many needle-like crystals could be attributed to a kind of self-organization in order to reduce surface energy $[18,40,41]$. Despite showing a similarity in shape, the samples in the present study showed different particle size, the diameter of the aggregates being approximately $2-4 \mu \mathrm{m}, 4-8 \mu \mathrm{m}$, and 5-10 $\mu \mathrm{m}$ at 1,2 , and $6 \mathrm{~h}$, respectively. It was mentioned earlier that aragonite crystals with smaller sizes are more suitable for seeds in order to clearly demonstrate the effects of carboxylic acid. Although the aragonite synthesized at $1 \mathrm{~h}$ has a smaller particle size, the amount produced (i.e., yield) was not sufficient to be used as a seed for the series of systematic co-precipitation experiments. Therefore, a 2-h reaction time was selected for the seed preparation condition. The average particle size of aragonite seeds prepared by repeating five times at 2-h aging time was $6.54 \mu \mathrm{m}$ (Figure 3), which is as depicted in the SEM image (Figure 2B). 

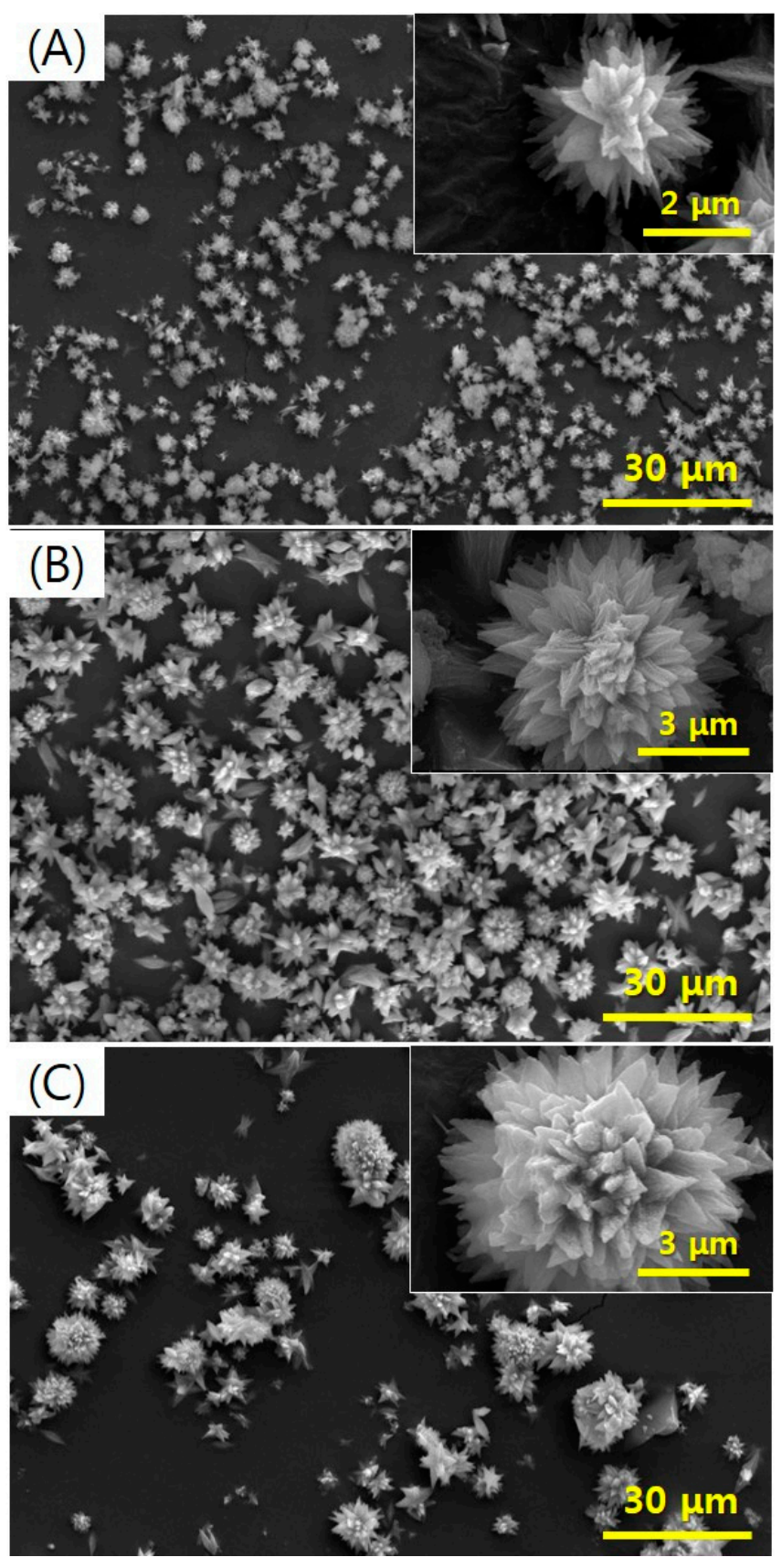

Figure 2. SEM images for samples synthesized at different aging times without organic acids. (A) $1 \mathrm{~h}$, (B) $2 \mathrm{~h}$, and (C) $6 \mathrm{~h}$. 


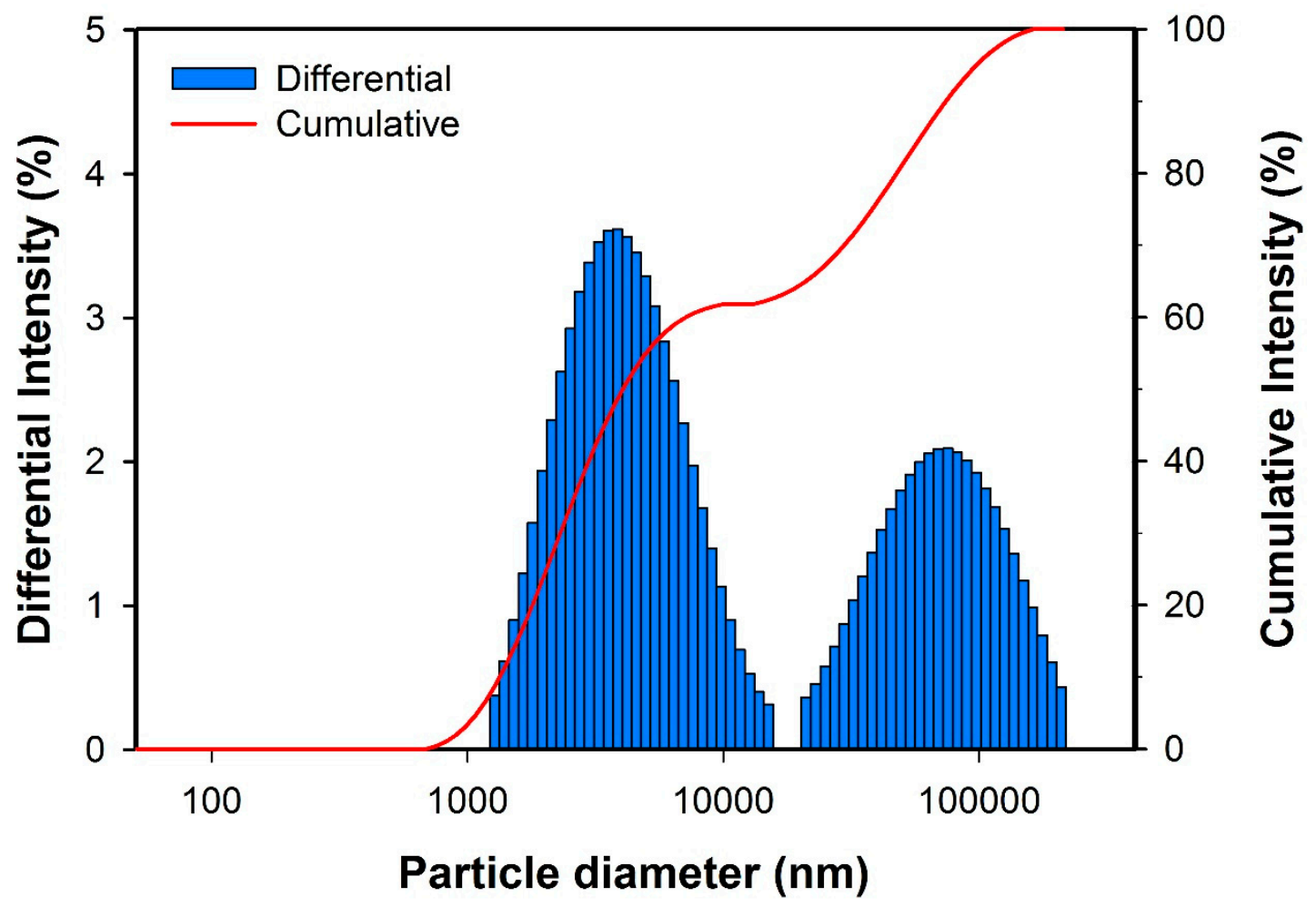

Figure 3. Particle size distribution of aragonite seed prepared at 2-h reaction time. The weak second peak might be caused by aggregation of the aragonite particles shown in the first peak.

\subsection{Characterization of Organic Co-Precipitated Aragonite}

\subsubsection{XRD}

Figure 4 shows the XRD patterns of the aragonite seed (2-h-aged) and the aragonite samples synthesized by the seeded co-precipitation method (seed + overgrowth) under the different types of 1-mM carboxylic acid conditions with $0.1 \mathrm{~g}$ of aragonite seed. The refined structural parameters and crystallite sizes of the as-synthesized aragonite samples were calculated by Rietveld refinement with the XRD data and are listed in Table 2.

Although there is a difference in intensity, all synthesized samples exhibited the typical XRD pattern of aragonite (JCPDS No. 01-078-4339), indicating that aragonite was formed in our experimental condition without any other mineral phases. In addition, the values of the structural parameters of all samples were within the ranges of 4.960-4.963 $\AA$ (a-axis), 7.966-7.978 $\AA$ (b-axis), and 5.746-5.749 (c-axis), which are consistent with the experimental values: $a=4.960 \AA, b=7.964 \AA$, and c $=5.738 \AA$ [42].

Compared to the XRD pattern of the used aragonite seed (2-h), those of the control sample (formed by the overgrowth of seed in the absence of carboxylic acid) showed a remarkable increase in crystallinity corresponding to the increase in crystallite size from 79.3 to $136.4 \mathrm{~nm}$ without significant changes in the structural parameters (Table 2). This means that aragonite crystal was epitaxially overgrown at the (111) plane of the substrate (i.e., aragonite seed) without significant changes in the lattice structure of aragonite [43]. In contrast, those of the organic co-precipitated aragonite samples synthesized in the presence of carboxylic acids that have different numbers of carboxyl functional groups (i.e., Case 1, see Table 1) showed a distinctive difference (i.e., decrease) in crystallinity, and this was dependent on the number of carboxyl functional groups. In addition, the crystallite sizes of aragonite formed in citric acid and malic acid were 27.4 and $54.3 \mathrm{~nm}$, respectively, which were significantly smaller than those of control sample $(136.4 \mathrm{~nm})$, indicating a retardation of crystal growth by the two carboxylic acids. In addition to the dramatic reduction of crystallite size, citric-arag (aragonite co-precipitated with citric acid) showed a slight change in structural parameters (i.e., a-, b-, 
and c-axes). Although our XRD data were acquired by a conventional XRD equipment and caution is needed in interpretation, we believe that the slight change in the structural parameters for citric-arag is meaningful. These results indicate that the crystallite size and the crystal lattice of aragonite formed in the presence of carboxylic acids can be affected by the number of carboxyl functional groups.

However, glutamic acid and phthalic acid, which have different functional groups and hydrocarbon structures with malic acid (Case 2), showed no significant changes in crystallinity even though they have two carboxyl groups. This probably indicates that the presence of amino functional groups in the glutamic acid and different hydrocarbon structures (e.g., cyclic) in phthalic acid can attenuate the effects of carboxylic acid on the crystallinity of aragonite.

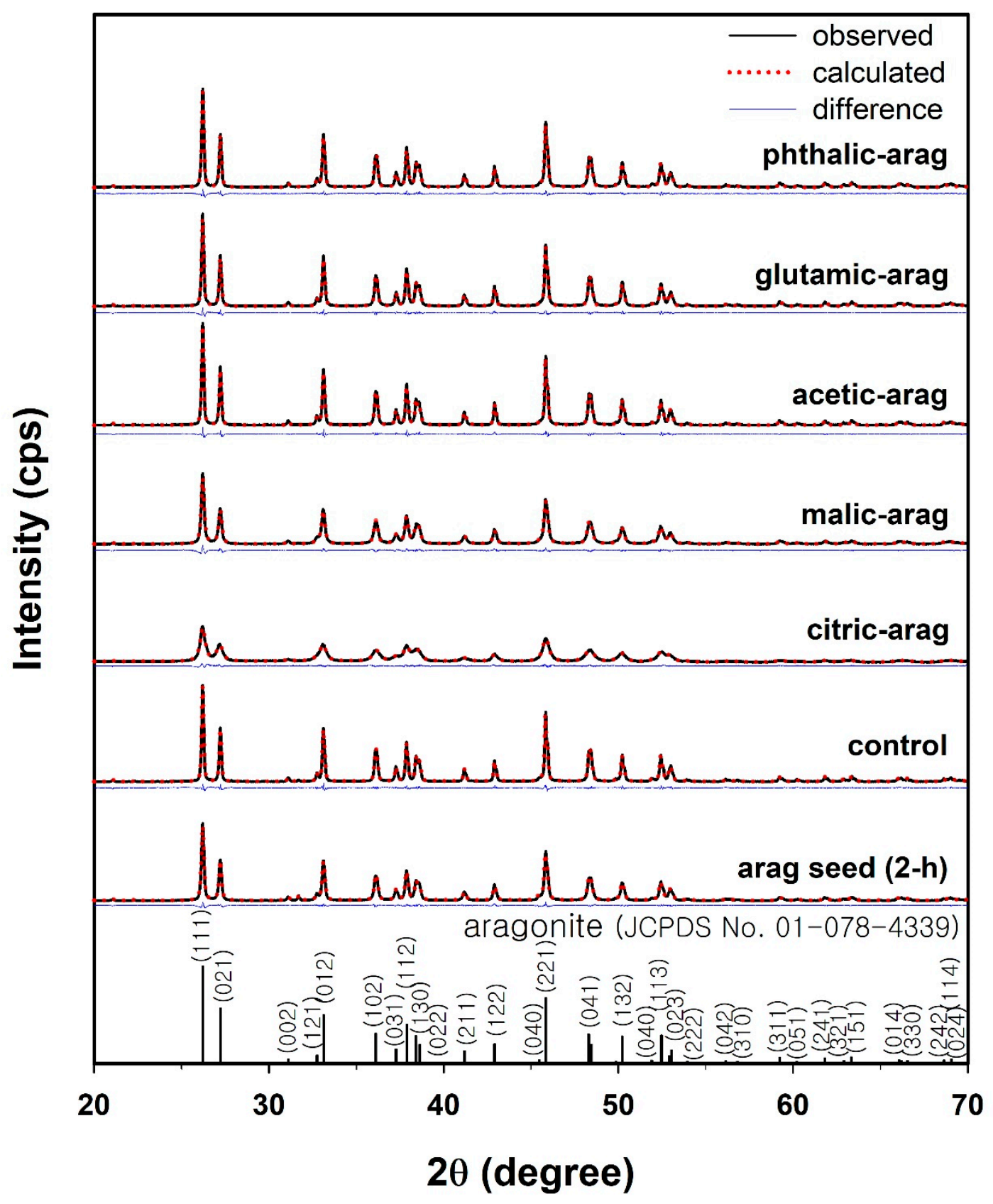

Figure 4. XRD patterns for the used aragonite seed (2-h) and the organic co-precipitated aragonite samples. 
Table 2. Refined structural parameters and crystallite sizes of the used aragonite seed and the organic co-precipitated aragonite samples.

\begin{tabular}{cccccccc}
\hline \multirow{2}{*}{$\begin{array}{c}\text { Sample Type of } \\
\text { Aragonite }\end{array}$} & \multicolumn{2}{c}{ Structural Parameters $^{\mathbf{a}}(\mathbf{\AA})$} & \multirow{2}{*}{$\begin{array}{c}\text { Crystallite } \mathbf{s i z e} \\
(\mathbf{n m})\end{array}$} & $\mathbf{R}_{\mathbf{w p}}{ }^{\mathbf{c}}$ & $\mathbf{R}_{\mathbf{e x p}} \mathbf{d}^{\mathbf{b}}$ & $\mathbf{G O F}^{\mathbf{e}}$ \\
\cline { 2 - 4 } & a-axis & $\mathbf{b}$-axis & c-axis & & & \\
\hline arag seed (2-h) & $4.9630(9)$ & $7.969(17)$ & $5.747(11)$ & $79.3 \pm 1.3$ & 7.17 & 6.22 & 1.15 \\
\hline control & $4.9629(7)$ & $7.966(12)$ & $5.7470(9)$ & $136.4 \pm 3.1$ & 8.16 & 6.93 & 1.18 \\
\hline citric-arag & $4.960(29)$ & $7.978(58)$ & $5.749(36)$ & $27.4 \pm 0.5$ & 7.11 & 5.68 & 1.25 \\
\hline malic-arag & $4.962(14)$ & $7.969(25)$ & $5.749(16)$ & $54.3 \pm 0.7$ & 8.14 & 6.37 & 1.28 \\
\hline acetic-arag & $4.9625(7)$ & $7.966(13)$ & $5.747(00)$ & $127.1 \pm 2.8$ & 7.81 & 6.63 & 1.18 \\
\hline glutamic-arag & $4.9627(8)$ & $7.966(14)$ & $5.746(10)$ & $100.7 \pm 1.7$ & 7.87 & 6.85 & 1.15 \\
\hline phthalic-arag & $4.9624(8)$ & $7.966(15)$ & $5.746(10)$ & $111.3 \pm 2.3$ & 7.85 & 6.65 & 1.18 \\
\hline
\end{tabular}

Note: The refined structural parameters and crystallite sizes were obtained through Rietveld refinement on the XRD data. The (values) included in the structural parameters indicate the error range. ${ }^{a}$ Length of $a, b$, and c-axes.

${ }^{b}$ Estimated size of aragonite crystallite calculated from the (111) reflection. ${ }^{c}$ Weighted sum of squared residuals.

${ }^{\mathrm{d}}$ Possible minimum value for $\mathrm{R}_{\mathrm{wp}} .{ }^{\text {e }}$ Goodness of Fit, GOF $=\mathrm{R}_{\mathrm{wp}} / \mathrm{R}_{\exp }$.

\subsubsection{TEM/SAED}

Figure 5 shows TEM images and SAED patterns of co-precipitated aragonite samples synthesized at different types of carboxylic acids with $1 \mathrm{mM}$ concentration. The control sample (Figure 5A) shows a needle-like single crystal that can gather together to form a spherulite structured particle as observed in the SEM images (see Figure 6A). The SAED pattern of the control sample shows a regular arrangement of diffraction spots (white points), which are related to the series of electrons diffracted on the crystal plane. This means that the control sample has a constant lattice and symmetry structure and consequently high crystallinity by the epitaxial crystal growth.
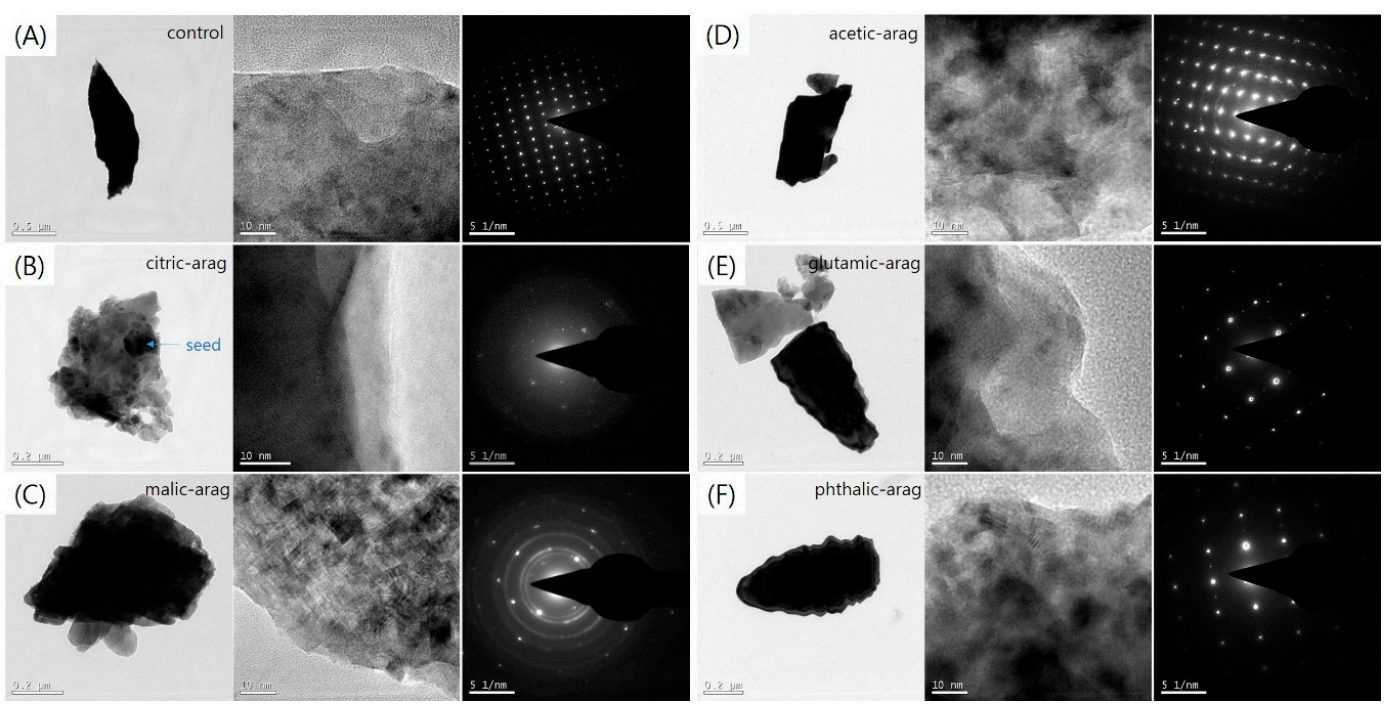

Figure 5. TEM images (left) and selected area electron diffraction (SAED) patterns (right: derived from the middle images, which are the magnified left TEM images) for the co-precipitated aragonite samples. (A) Control, (B) citric-arag, (C) malic-arag, (D) acetic-arag, (E) glutamic-arag, and (F) phthalic-arag.

In contrast, significant changes in the crystal shape and lattice structure were observed in the aragonite samples synthesized in the presence of carboxylic acids, with different numbers of carboxyl groups (i.e., Case 1, see Table 1). The citric-arag sample synthesized in the presence of citric acid (Figure 5B) was observed to have many small crystals attached to an aragonite seed (dark black in the left image). This is in contrast to the control sample, which showed aragonite overgrowth through the successive extension of the seed surface lattice structure, indicating that the epitaxial growth of 
aragonite crystals was strongly inhibited due to surface poisoning by the adsorption of citric acid on the aragonite seed $[14,32,44]$. Instead, new small aragonite crystals formed by co-precipitation with citric acid were attached to the surface of the pre-existing aragonite seed. According to previous studies, interactions with citrate cause the large defect in the surface structure of calcite [45]. During the crystallization of carbonate minerals, this can lead to the partial lattice disorder that can be confirmed in SAED patterns $[46,47]$. Thus, it is thought that the irregular SAED pattern with weak diffraction spots and the polycrystalline concentric circles in the citric-arag sample possibly indicate that the growth in the direction of crystal planes was strongly inhibited due to the citrate induced-defect structure accompanying with the significant disorder. Such polycrystalline properties were also observed in the aragonite samples synthesized in the presence of malic acid and acetic acid (Figure 5C,D)). However, when the number of carboxyl groups in the used carboxylic acids decreased (i.e., citric $3>$ malic 2 $>$ acetic 1), the following tendency was clearly observed: (1) a single aragonite crystal grew more, (2) polycrystalline concentric circles in the SAED pattern became faint, and (3) diffraction spots were more evident and regularly arranged with less disorder in crystal lattice.

Contrastingly, glutamic-arag and phthalic-arag samples synthesized in the presence of glutamic and phthalic acids (Figure 5E,F) showed similar crystal morphology to the needle-like pure aragonite crystal with regular SAED patterns (Figure 5A). This means that glutamic acid and phthalic acid do not significantly affect the growth of aragonite crystals and the crystal lattice. These TEM/SAED results are consistent with the XRD results, which show that the carboxylic acids with two carboxyl groups (malic acid) have a great influence on the growth and structural properties of aragonite crystals, but the effects are strongly suppressed by the presence of amino groups or cyclic structures.

\subsubsection{HPLC}

HPLC analysis was performed on the aragonite samples synthesized under the conditions of different types and concentrations of carboxylic acids to measure the quantitative amount of carboxylic acids in the aragonite samples (see Table 3). Interestingly, other carboxylic acids were not detected, although the content of citric and malic acids increased with their concentration in the synthetic solution. In addition, the amount of citric acid incorporated increased steadily from 0.23 to $0.65 \mathrm{wt} \%$ as the carboxylic acid concentration in the synthetic solution increased from 0.1 to $1.0 \mathrm{mM}$, but malic acid reached a maximum at $0.19 \mathrm{wt} \%$. These results can support the XRD and TEM/SAED results, which showed a disorder in the lattice structure of carbonate mineral upon the incorporation of citric and malic acids [34]. Therefore, it is suggested that only the two carboxylic acids can be favorably incorporated into aragonite, and this tendency is stronger in citric acid than malic acid.

Table 3. The incorporated contents of carboxylic acids in the organic co-precipitated aragonite samples measured by HPLC.

\begin{tabular}{ccccccc}
\hline $\begin{array}{c}\text { Concentration of a } \\
\begin{array}{c}\text { Carboxylic Acid in } \\
\text { Synthetic Solution (mM) }\end{array}\end{array}$ & \multicolumn{6}{c}{ The Incorporated Contents of Carboxylic Acids in Aragonite Samples (wt \%) } \\
\cline { 2 - 7 } & Control & $\begin{array}{c}\text { Citric- } \\
\text { Arag }\end{array}$ & $\begin{array}{c}\text { Malic- } \\
\text { Arag }\end{array}$ & $\begin{array}{c}\text { Acetic- } \\
\text { Arag }\end{array}$ & $\begin{array}{c}\text { Glutamic- } \\
\text { Arag }\end{array}$ & $\begin{array}{c}\text { Phthalic- } \\
\text { Arag }\end{array}$ \\
\hline 0.1 & - & 0.23 & 0.04 & $0.01 \downarrow$ & $0.01 \downarrow$ & $0.01 \downarrow$ \\
\hline 0.5 & - & 0.53 & 0.19 & $0.01 \downarrow$ & $0.01 \downarrow$ & $0.01 \downarrow$ \\
\hline 1.0 & $0.01 \downarrow$ & 0.65 & 0.19 & $0.01 \downarrow$ & $0.01 \downarrow$ & $0.01 \downarrow$ \\
\hline
\end{tabular}

\subsubsection{SEM}

Figure 6 shows the morphology of the co-precipitated aragonite samples. The control sample formed in the absence of carboxylic acid showed a flower-like particle approximately $30 \mu \mathrm{m}$ in diameter, which was fabricated by the aggregation of many needle-like or prismatic-shaped aragonite crystals (Figure 6A). This is about five times the size of the aragonite seed (see Figure 2B), and it indicates that the pure aragonite formed in the absence of carboxylic acid was overgrown from the seed during the co-precipitation experiment [48]. Compared to the control sample, the citric-arag sample showed 
distinctive changes in crystal morphology. The flower-like particle shape with many needle-like or prismatic single crystals shown in the control sample changed to a grape-cluster-like particle shape with a bumpy surface (Figure 6B). Such morphological changes were also observed in the malic-arag sample, which also reduced the crystallinity of the sample (Figure 6C). However, this tendency was stronger in the citric-arag than in the malic-arag. On the other hand, the acetic-arag, the glutamic-arag, and the phthalic-arag samples showed no significant changes in crystal morphology (Figure 6D-G), although there was a small difference in the aspect ratio. Based on these SEM results, it can also be confirmed that the Case 1 carboxylic acids, which contain different numbers of carboxyl groups in the structure, have the greatest influence on the crystallinity as well as the crystal morphology of the co-precipitated aragonite. In addition, these effects increase with the number of carboxylic acid groups and decrease when there are other functional groups (i.e., an amino group) or cyclic structures in the structure. These SEM observations, along with the XRD, TEM/SAED, and HPLC results, indicate that the crystallinity and crystal shape of synthesized aragonite can be significantly changed by incorporation of the carboxylic acids into aragonite, especially in the presence of citric and malic acids.
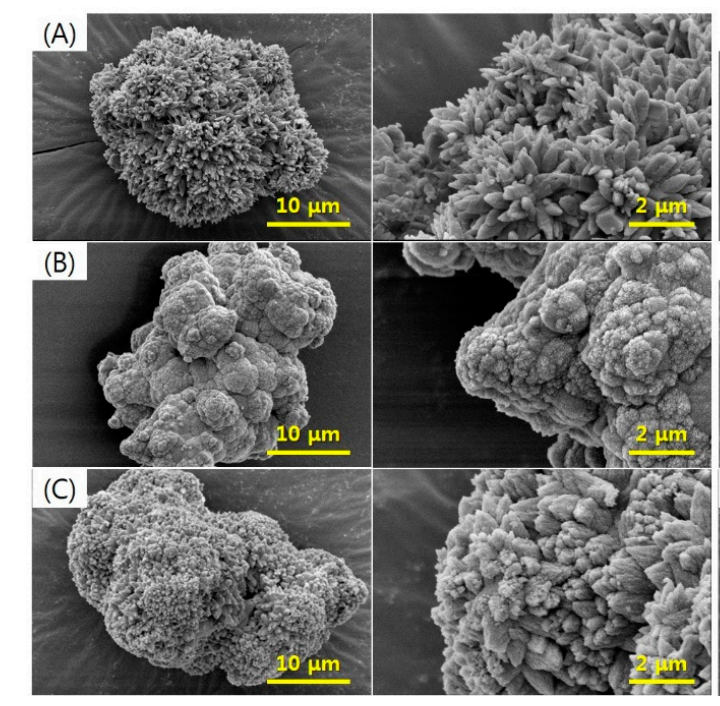

Figure 6. SEM images for the co-precipitated aragonite samples.

(C) malic-arag, (D) acetic-arag, (E) glutamic-arag, and (F) phthalic-arag.

\subsubsection{FT-IR}

Figure 7A shows the FT-IR spectra of the co-precipitated aragonite samples. The FT-IR spectrum of the control sample shown in Figure 7B is consistent with the previously reported spectra of aragonite [49-51]. The two characteristic absorption peaks positioned at 700 and $713 \mathrm{~cm}^{-1}$ are assigned to the carbonate $v_{4}$ vibration of aragonite. The strong peak at $855 \mathrm{~cm}^{-1}$ is assigned to out-of-plane bending $v_{2}$ vibration, whereas the peak at $1083 \mathrm{~cm}^{-1}$ corresponds to the symmetric carbonate $v_{1}$ stretching vibration. The other strong peak centered at $1460 \mathrm{~cm}^{-1}$ is assigned to asymmetric carbonate $v_{3}$ stretching vibration and considered to be the major feature of the carbonate ion. The weak peak at $1787 \mathrm{~cm}^{-1}$ is attributed to the combined peak of $v_{1}$ and $v_{4}$ vibrations. This result reveals that the control sample synthesized in this study shows typical aragonite properties. 
(A)

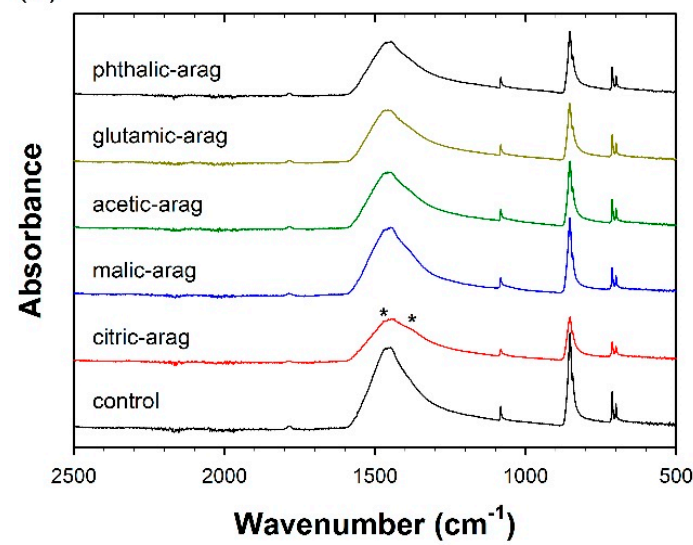

(B)

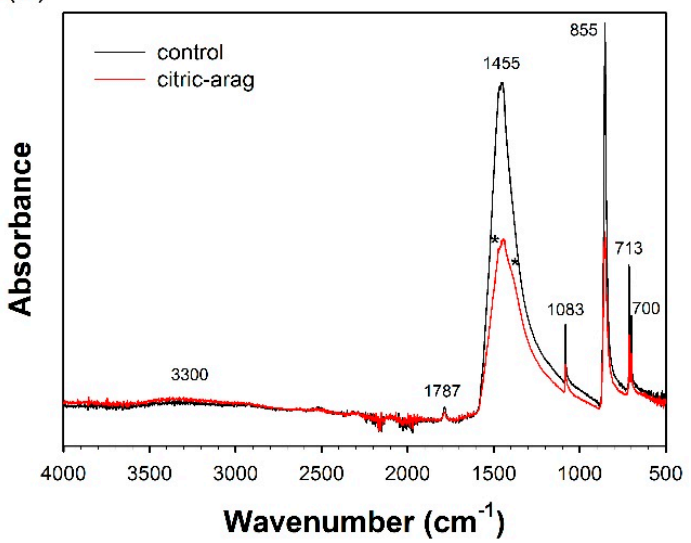

Figure 7. (A) Fourier transform-infrared (FT-IR) spectra of the co-precipitated aragonite samples. (B) Comparison of the control and the citric-arag samples. Weak feature $\left(^{*}\right)$ is described in the text.

Interestingly, the aragonite samples co-precipitated with carboxylic acids showed a slight decrease in the absorbance intensity but were almost similar to those of the control sample (Figure 7A). Phillips et al. (2005), who studied organic ligand co-precipitation with calcite using NMR spectroscopy, reported that calcite grown by a seeded constant-addition method can contain about $1 \mathrm{wt} \%$ of citrate [52]. This was proved by Lee and Reeder (2006), who studied the role of citrate during Co(II) co-precipitation with calcite using thermogravimetric analysis (TGA) and FT-IR [33]. Although the amount of citrate $(0.65 \mathrm{wt} \%)$ in our citric-arag sample is less than the reported value $(1 \mathrm{wt} \%)$ and close to the detection limit of FT-IR, making it difficult to clearly confirm the change, two indirect evidences of citrate incorporation were confirmed in the FT-IR spectra. First, the weak shoulders positioned near $1455 \mathrm{~cm}^{-1}$ (indicated by *) are within the banding range corresponding to the typical stretching modes of the carboxyl group, indicating the existence of citrate in the citric-arag sample [33]. Second, the broad feature around $3300 \mathrm{~cm}^{-1}$ might be attributable to the stretching modes of structural water [53], which could have been inserted together during the process of citrate incorporation into the aragonite structure $[33,34]$. These FT-IR results can support the fact that citrate was incorporated into the aragonite structure.

\subsubsection{TG-DSC}

The TG-DSC profiles of the control and citric-arag samples are presented in Figure 8. During the TG analysis (Figure 8A), the control sample exhibited a first slight weight loss in the range of $85-110^{\circ} \mathrm{C}$ and a second weight loss of around $324.6{ }^{\circ} \mathrm{C}$, owing to the dehydration of physically adsorbed water and crystal water in aragonite, respectively [54]. In contrast, the citric-arag sample showed a more significant weight loss up to $324.6^{\circ} \mathrm{C}$, which might be due to the introduction of more water molecules into the distorted structure of aragonite $\left(\mathrm{CaCO}_{3}\right)$ together with citrate incorporation $[52,55]$. In addition, a strong endothermic peak at $439.3^{\circ} \mathrm{C}$ was observed in the DSC profile of the citric-arag sample (Figure $8 \mathrm{~B})$, and it exhibited a greater weight loss $(0.75 \%)$ than the control sample $(0.11 \%)$ in the temperature range of $422.5-455.8^{\circ} \mathrm{C}$. Similarly, Lee and Reeder (2006) also confirmed that citrate-incorporated calcite, which is another polymorph of $\mathrm{CaCO}_{3}$, had $\approx 1 \%$ total weight loss between 375 and $550{ }^{\circ} \mathrm{C}$, and they suggested that this is attributable to the decomposition of the incorporated citrate in the calcite structure [33]. Considering the similarity of TG analysis results between the two studies, it is possible that the sharp endothermic peak at $439.3^{\circ} \mathrm{C}$ in the DSC profile of the citric-arag sample could be attributed to the decomposition of citrate, which was incorporated into the aragonite structure during crystallization. Interestingly, the difference in weight loss of $0.64 \%$ between the control sample $(0.11 \%)$ and the citric-arag $(0.75 \%)$ in the temperature range $\left(422.5-455.8{ }^{\circ} \mathrm{C}\right)$, in which significant weight loss occurred due to citrate decomposition, agreed well with the citric acid content 
of $0.65 \%$ measured by HPLC (Table 3). These results also support the fact that citrate was incorporated into the aragonite structure.

(A)

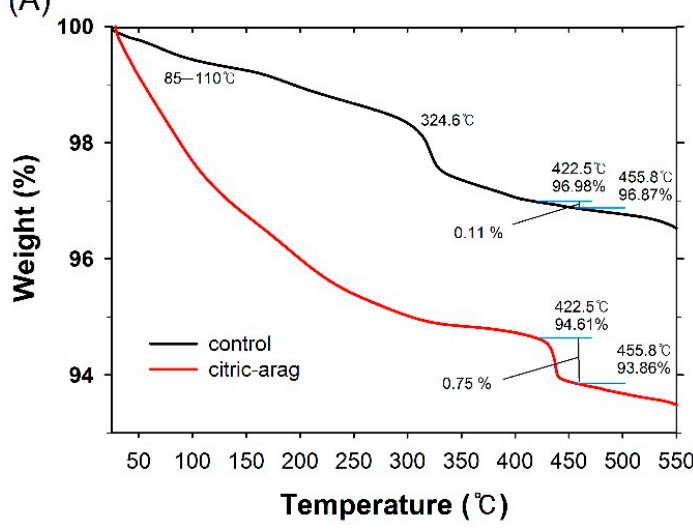

(B)

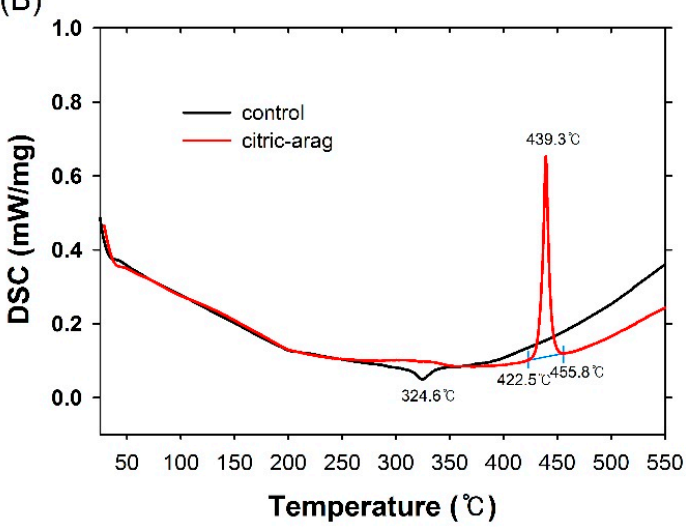

Figure 8. Thermogravimetric and differential scanning calorimetry (TG-DSC) results of the control and citric-arag samples. (A) Weight-loss curves and (B) DSC profiles.

\subsection{Theoretical Speciation Modeling}

To further explain why different types of carboxylic acids have different incorporation properties into aragonite, species calculation for the used carboxylic acids was carried out. In this study, as shown in Table 1 , the carboxylic acids with each $p K a$ value $\left(\mathrm{pKa}_{3}=6.40\right.$ for citric acid; $\mathrm{pKa}_{2}=5.20$ for malic acid; $\mathrm{pKa}_{1}=4.76$ for acetic acid; $\mathrm{pKa}_{2}=4.07$ for glutamic acid; $\mathrm{pKa}_{2}=5.51$ for phthalic acid) were fully deprotonated because the $\mathrm{pH}$ of the mixed solution was kept at $\approx 8.3$ during the co-precipitation (Figure S2). This means that some of the deprotonated carboxylic acids can exist in the form of Ca-organic ligand complexes (i.e., chelate). According to the previous studies, the metal chelate complex species such as (Ca-citrate) $)^{-}$can be strongly involved in its incorporation into carbonate minerals such as calcite or siderite $[33,34,52]$. Therefore, we deduced that the Ca-organic ligand complexes have an important role in the incorporation of carboxylic acids into aragonite.

The speciation modeling results for the different carboxylic acids are presented in Figure 9, showing the predominance of species as a function of $\mathrm{pH}$. In Case 1, carboxylic acids and most of the citric acid species exist as (Ca-citrate) $)^{-}$, while malic acid exists as $80 \%$ of $(\mathrm{Ca}-\text { malate })^{0}$ and $20 \%$ of (malate $)^{2-}$,

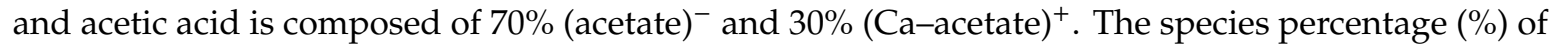
$\mathrm{Ca}$-organic ligand decreases in the order citric acid $>$ malic acid $>$ acetic acid, which is consistent with the number of carboxyl groups and the order of the amount of incorporation (see Table 3). According to Geffroy et al. (1999), when calcite $\left(\mathrm{CaCO}_{3}\right)$ is hydrated in water, there is a substantial number of positive sites in the crystal surfaces [56]. This means that the more negatively charged Ca-organic ligand complex has a stronger affinity to the positively charged aragonite surface and can be readily incorporated into the surface lattice structure of aragonite crystals. In the speciation modeling of Case 1 carboxylic acids, the (Ca-citrate $)^{-}$complex has a negative charge, whereas $(\mathrm{Ca}-\text { malate })^{0}$ and $(\mathrm{Ca}-\text { acetate })^{+}$have a neutral charge and positive charge, respectively. Therefore, considering the predominance of $\mathrm{Ca}$-organic ligands and their electrostatic attraction-repulsion to the crystal surface, it could be explained that the incorporation of Case 1 carboxylic acids into aragonite is favorable in the order of citric acid $>$ malic acid $>$ acetic acid. 
(A)

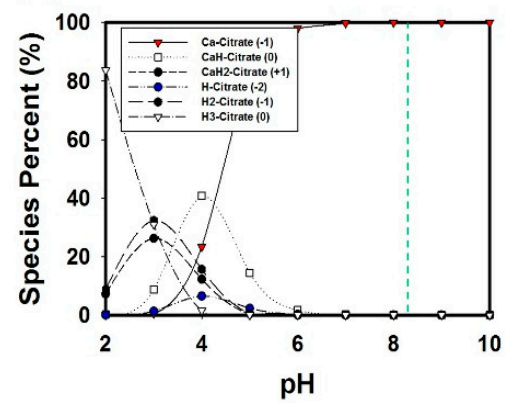

(D)
(B)

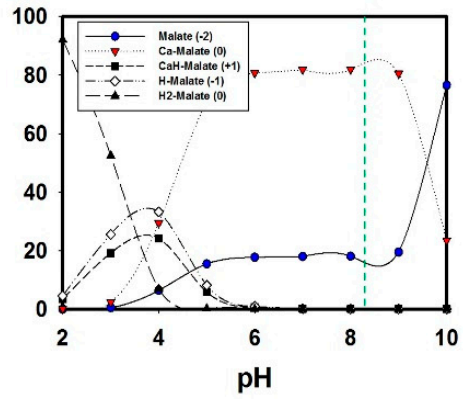

(C)

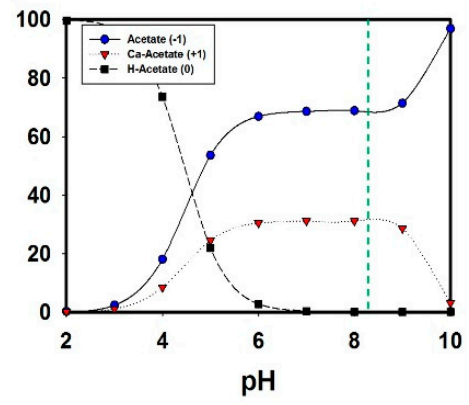

(E)
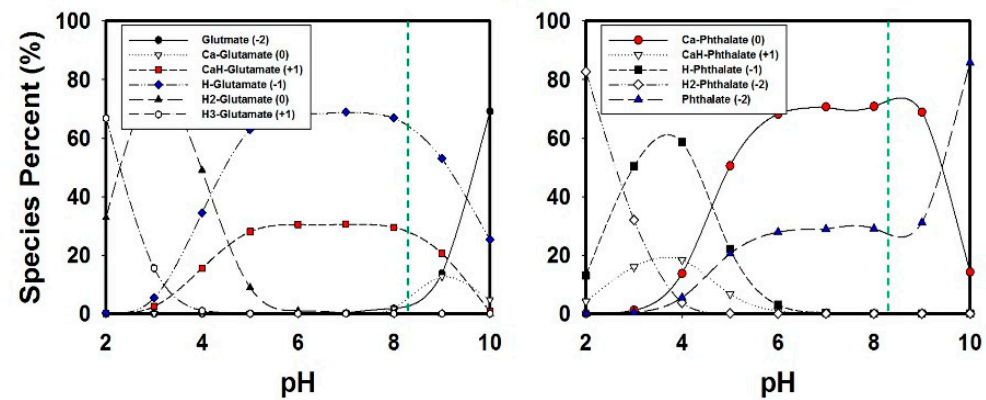

Figure 9. Predominance diagram for organic acid speciation in pre-equilibrated aragonite as a function of $\mathrm{pH}$ at the conditions of solution including $\left[\mathrm{Ca}^{2+}\right]_{\text {initial }}=7 \mathrm{mM}$, [organic acids $]_{\text {initial }}=1 \mathrm{mM}$. (A) Citric acid, (B) malic acid, (C) acetic acid, (D) glutamic acid, and (E) phthalic acid. The green dashed line is positioned at $\mathrm{pH} 8.3$.

In Case 2, carboxylic acids, glutamic acid, and phthalic acid have the same number of carboxyl groups but different types of functional groups (amino groups) or organic structures (cyclic) compared to malic acid. The amino group of glutamic acid was not deprotonated because of the higher $\mathrm{pKa}$ value $\left(\mathrm{pKa}_{3}=9.47\right)$ than the mixed solution $\mathrm{pH}$ of 8.3 ; hence, most of the glutamic acid existed as $(\mathrm{H} \text {-glutamate })^{-}$or $(\mathrm{CaH} \text {-glutamate })^{+}$. The percentage of $(\mathrm{CaH} \text {-glutamate })^{+}$species was less than $30 \%$, and the species while bearing a positive charge may not easily bind to the aragonite surface owing to electrostatic repulsion. This may explain why glutamic acid was not incorporated into the aragonite. Meanwhile, most of the phthalic acid species exists as (Ca-phthalate $)^{0}$, but it has a neutral charge as well as a hydrophobic aromatic ring structure with no sites for the further attachment of either $\mathrm{Ca}^{2+}$ or $\mathrm{CO}_{3}{ }^{2-}$ (see Table 1). It was thought that the incorporation of phthalic acid into aragonite was difficult owing to such electrostatic contributions and hydrophobic structural character.

The results stated above explain why citric acid among the various carboxylic acids was most favorably incorporated into aragonite. The favorable incorporation of citric acid inhibited the growth of aragonite crystals and caused a dramatic change in the crystallinity and crystal morphology compared to other carboxylic acids. In our co-precipitation experiment using a seeded constant-addition method in the presence of carboxylic acids, the possible mechanism for the preferential incorporation of citric acid into aragonite was deduced as the following three-step process (Figure 10). (1) Chelation: Citric acid in the growth solution is fully deprotonated at $\mathrm{pH} 8.3$, exists as (citrate) ${ }^{3-}$, and is coupled with $\mathrm{Ca}^{2+}$ ions to form metal-organic complex, (Ca-citrate) $)^{-}$. (2) Adsorption: Some of the (Ca-citrate) $)^{-}$can be adsorbed on the surface of aragonite seed crystals, mainly $\mathrm{Ca}^{2+}$ of $(\mathrm{Ca}-\mathrm{citrate})^{-}$is bound to $\mathrm{CO}_{3}{ }^{2-}$ on the surface of aragonite seeds [33]. (3) Co-precipitation: When an additional reaction solution with a high concentration of $\mathrm{Ca}^{2+}$ and $\mathrm{CO}_{3}{ }^{2-}$ is introduced, aragonite crystal is overgrown at the periphery site where $(\mathrm{Ca}-\text { citrate })^{-}$is pre-adsorbed. 
(1) chelation
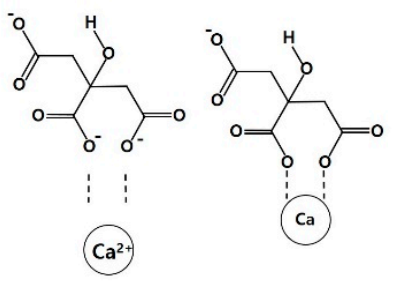

(2) adsorption

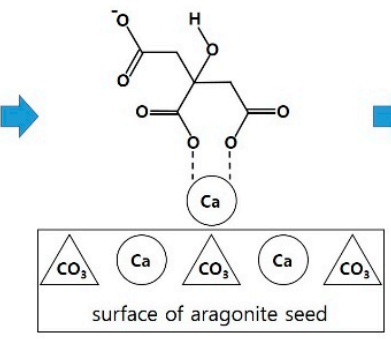

(3) co-precipitation

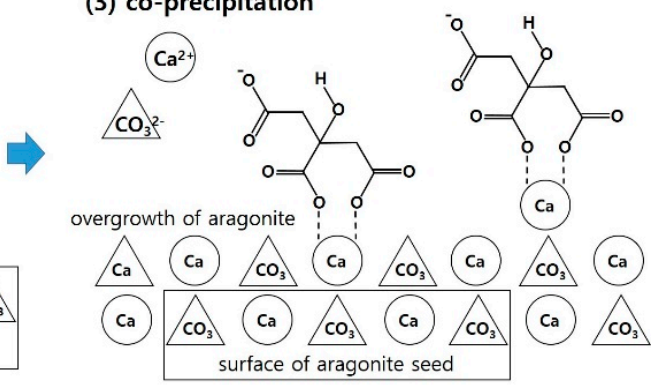

Figure 10. Schematic illustration of the incorporation mechanism of citric acid into aragonite.

\section{Conclusions}

The effects of the preferential incorporation of carboxylic acids on the crystal growth and physicochemical properties of synthetic aragonite were investigated. The methodology involved a systematic study through a seeded co-precipitation experiment in the presence of carboxylic acids, various liquid- and solid-state characterizations, and speciation modeling interpretation. The aragonite crystals were synthesized in the presence of different carboxylic acids, and significant differences were observed in their growth and the physicochemical properties such as crystallinity, crystal morphology, and chemical composition (i.e., organic content). These differences reflect that the number and type of functional groups as well as the structural conformation are important factors for the incorporation of carboxylic acid groups. Based on speciation modeling, the predominance of the negatively charged metal-organic complex, (Ca-citrate) ${ }^{-}$, which has a strong affinity to the aragonite surface, was suggested as one of the reasons why citric acid could be most favorably incorporated into aragonite among the used carboxylic acids. The investigated incorporation properties and mechanisms of various carboxylic acids will provide valuable information to explore the applicability of aragonite in various industrial fields as well as improve the understanding of crystal growth through the biomineralization of aragonitic crystals.

Supplementary Materials: The following are available online at http://www.mdpi.com/2073-4352/10/11/960/s1, Figure S1: Saturation index of calcium carbonates as a function of $\mathrm{pH}$ of the initial growth solution calculated by PHREEQC software with the sit.dat database. Modeling conditions: $\left[\mathrm{Ca}^{2+}\right]$ and $\left[\mathrm{CO}_{3}{ }^{2-}\right]=7 \mathrm{mM},[\mathrm{NaCl}]=0.1 \mathrm{M}$, $\left[\mathrm{MgCl}_{2}\right]=0.05 \mathrm{M}$ and equilibrium with $\mathrm{CO}_{2}(\mathrm{~g}) 10^{-3.5} \mathrm{~atm}$. Figure S2: $\mathrm{pH}$ variation in the mixed solutions during organic co-precipitation experiments.

Author Contributions: Conceptualization, S.Y.L., U.J., Y.J.L., Methodology, S.Y.L., U.J., B.C; software, S.Y.L., U.J., B.C.; validation, S.Y.L.; formal analysis, U.J., S.Y.L., B.C.; investigation, S.Y.L., U.J., Y.J.L.; resources, Y.J.L., S.Y.L.; data curation, S.Y.L., B.C.; writing—original draft preparation, U.J., S.Y.L.; writing-review and editing, S.Y.L., Y.J.L., B.C.; visualization, S.Y.L., U.J., B.C.; supervision, Y.J.L.; project administration, Y.J.L., S.Y.L.; funding acquisition, Y.J.L., S.Y.L. All authors have read and agreed to the published version of the manuscript.

Funding: This work was supported by grants from the National Research Foundation of Korea funded by the Korea government (grant numbers 2020R1I1A1A01073846 and 2020R1F1A1069495), and the Korea Environment Industry \& Technology Institute through the Underground Environmental Pollution Risk Management Technology Development Business Program funded by the Korea Ministry of Environment (grant number 2018002470002).

Acknowledgments: This work was also supported by a Korea University Grant and the Korea University Future Research Grant (KU-FRG).

Conflicts of Interest: The authors declare no conflict of interest.

\section{References}

1. Ahmed, K.M.; Bhattacharya, P.; Hasan, M.A.; Akhter, S.H.; Alam, S.M.; Bhuyian, M.H.; Iman, M.B.; Khan, A.A.; Sracek, O. Arsenic enrichment in groundwater of the alluvial aquifers in Bangladesh: An overview. Appl. Geochem. 2004, 19, 181-200. [CrossRef]

2. de Leeuw, N.H.; Parker, S.C. Surface structure and morphology of calcium carbonate polymorphs calcite, aragonite, and vaterite: An atomistic approach. J. Phys. Chem. B 1998, 102, 2914-2922. [CrossRef] 
3. Fellner, P.; Jurisova, J.; Pach, L. Preparation of needle-like aragonite particles from calcium nitrate solution. Acta Chim. Slovaca 2011, 4, 3-10.

4. Santos, R.M.; Ceulemans, P.; Van Gerven, T. Synthesis of pure aragonite by sonochemical mineral carbonation. Chem. Eng. Res. Des. 2012, 90, 715-725. [CrossRef]

5. Guo, H.; Qin, Z.; Qian, P.; Yu, P.; Cui, S.; Wang, W. Crystallization of aragonite $\mathrm{CaCO}_{3}$ with complex structures. Adv. Powder Technol. 2011, 22, 777-783. [CrossRef]

6. Wang, L.; Sondi, I.; Matijević, E. Preparation of uniform needle-like aragonite particles by homogeneous precipitation. J. Colloid Interface Sci. 1999, 218, 545-553. [CrossRef] [PubMed]

7. Thenepalli, T.; Jun, A.Y.; Han, C.; Ramakrishna, C.; Ahn, J.W. A strategy of precipitated calcium carbonate $\left(\mathrm{CaCO}_{3}\right)$ fillers for enhancing the mechanical properties of polypropylene polymers. Korean J. Chem. Eng. 2015, 32, 1009-1022. [CrossRef]

8. Li, G.; Li, Z.; Ma, H. Synthesis of aragonite by carbonization from dolomite without any additives. Int. J. Miner. Process. 2013, 123, 25-31. [CrossRef]

9. Wada, S.; Suzuki, H. Calcite and fluorite as catalyst for the Knövenagel condensation of malononitrile and methyl cyanoacetate under solvent-free conditions. Tetrahedron Lett. 2003, 44, 399-401. [CrossRef]

10. Matsumoto, M.; Fukunaga, T.; Onoe, K. Polymorph control of calcium carbonate by reactive crystallization using microbubble technique. Chem. Eng. Res. Des. 2010, 88, 1624-1630. [CrossRef]

11. Europe, C.C.A. Mineral Applications. 2011. Available online: https://www.ima-europe.eu/about-industrialminerals/industrial-minerals-ima-europe/calcium-carbonate (accessed on 26 September 2020).

12. El-Sheikh, S.M.; El-Sherbiny, S.; Barhoum, A.; Deng, Y. Effects of cationic surfactant during the precipitation of calcium carbonate nano-particles on their size, morphology, and other characteristics. Colloid Surface A 2013, 422, 44-49. [CrossRef]

13. Han, Y.S.; Hadiko, G.; Fuji, M.; Takahashi, M. Factors affecting the phase and morphology of $\mathrm{CaCO}_{3}$ prepared by a bubbling method. J. Eur. Ceram. Soc. 2006, 26, 843-847. [CrossRef]

14. Park, W.K.; Ko, S.J.; Lee, S.W.; Cho, K.H.; Ahn, J.W.; Han, C. Effects of magnesium chloride and organic additives on the synthesis of aragonite precipitated calcium carbonate. J. Cryst. Growth 2008, 310, 2593-2601. [CrossRef]

15. MacDonald, G.J. Experimental determination of calcite-aragonite equilibrium relations at elevated temperatures and pressures. Am. Mineral. 1956, 41, 744-756.

16. De Choudens-Sanchez, V.; Gonzalez, L.A. Calcite and aragonite precipitation under controlled instantaneous supersaturation: Elucidating the role of $\mathrm{CaCO}_{3}$ saturation state and $\mathrm{Mg} / \mathrm{Ca}$ ratio on calcium carbonate polymorphism. J. Sediment. Res. 2009, 79, 363-376. [CrossRef]

17. Wang, H.; Huang, W.; Han, Y. Diffusion-reaction compromise the polymorphs of precipitated calcium carbonate. Particuology 2013, 11, 301-308. [CrossRef]

18. Zhou, G.T.; Yao, Q.Z.; Ni, J.; Jin, G. Formation of aragonite mesocrystals and implication for biomineralization. Am. Mineral. 2009, 94, 293-302. [CrossRef]

19. Liu, R.; Xu, X.; Cai, Y.; Cai, A.; Pan, H.; Tang, R.; Cho, K. Preparation of calcite and aragonite complex layer materials inspired from biomineralization. Cryst. Growth Des. 2009, 9, 3095-3099. [CrossRef]

20. Han, Y.; Sun, B.; Yan, H.; Tucker, M.E.; Zhao, Y.; Zhou, J.; Zhao, Y.; Zhao, H. Biomineralization of Carbonate Minerals Induced by The Moderate Halophile Staphylococcus Warneri YXY2. Crystals 2020, 10, 58. [CrossRef]

21. Kim, Y.Y.; Ganesan, K.; Yang, P.; Kulak, A.N.; Borukhin, S.; Pechook, S.; Ribeiro, L.; Kröger, R.; Eichhorn, S.J.; Armes, S.P.; et al. An artificial biomineral formed by incorporation of copolymer micelles in calcite crystals. Nat. Mater. 2011, 10, 890-896. [CrossRef]

22. Currey, J.D. Mechanical properties of mother of pearl in tension. Proc. R. Soc. B 1977, 196, 443-463.

23. Tushtev, K.; Murck, M.; Grathwohl, G. On the nature of the stiffness of nacre. Mater. Sci. Eng. C 2008, 28, 1164-1172. [CrossRef]

24. Meyers, M.A.; Lin, A.Y.M.; Chen, P.Y.; Muyco, J. Mechanical strength of abalone nacre: Role of the soft organic layer. J. Mech. Behav. Biomed. 2008, 1, 76-85. [CrossRef]

25. Reddy, M.M.; Hoch, A.R. Calcite crystal growth rate inhibition by polycarboxylic acids. J. Colloid Interface Sci. 2001, 235, 365-370. [CrossRef]

26. Wada, N.; Kanamura, K.; Umegaki, T. Effects of carboxylic acids on the crystallization of calcium carbonate. J. Colloid Interface Sci. 2001, 233, 65-72. [CrossRef] 
27. Aschauer, U.; Spagnoli, D.; Bowen, P.; Parker, S.C. Growth modification of seeded calcite using carboxylic acids: Atomistic simulations. J. Colloid Interface Sci. 2010, 346, 226-231. [CrossRef]

28. Chaussemier, M.; Pourmohtasham, E.; Gelus, D.; Pécoul, N.; Perrot, H.; Lédion, J.; Cheap-Charpentier, H.; Horner, O. State of art of natural inhibitors of calcium carbonate scaling. A review article. Desalination 2015, 356, 47-55. [CrossRef]

29. Karar, A.; Naamoune, F.; Kahoul, A. Chemical and electrochemical study of the inhibition of calcium carbonate precipitation using citric acid and sodium citrate. Desalin. Water Treat. 2016, 57, 16300-16309. [CrossRef]

30. Manoli, F.; Dalas, E. Calcium carbonate crystallization in the presence of glutamic acid. J. Cryst. Growth 2001, 222, 293-297. [CrossRef]

31. Hoch, A.R.; Reddy, M.M.; Aiken, G.R. Calcite crystal growth inhibition by humic substances with emphasis on hydrophobic acids from the Florida Everglades. Geochim. Cosmochim. Acta 2000, 64, 61-72. [CrossRef]

32. Westin, K.J.; Rasmuson, Å.C. Crystal growth of aragonite and calcite in presence of citric acid, DTPA, EDTA and pyromellitic acid. J. Colloid Interface Sci. 2005, 282, 359-369. [CrossRef]

33. Lee, Y.J.; Reeder, R.J. The role of citrate and phthalate during Co (II) coprecipitation with calcite. Geochim. Cosmochim. Acta 2006, 70, 2253-2263. [CrossRef]

34. Lee, S.Y.; Kim, Y.; Chang, B.; Lee, Y.J. Enhanced Arsenic (III and V) Removal in Anoxic Environments by Hierarchically Structured Citrate/ $\mathrm{FeCO}_{3}$ Nanocomposites. Nanomaterials 2020, 10, 1773. [CrossRef]

35. Kim, S.; Chen, J.; Cheng, T.; Gindulyte, A.; He, J.; He, S.; Li, Q.; Shoemaker, B.A.; Thiessen, P.A.; Yu, B.; et al. PubChem 2019 update: Improved access to chemical data. Nucleic Acids Res. 2019, 47, 1102-1109. Available online: https://pubchem.ncbi.nlm.nih.gov/compound (accessed on 2 September 2020). [CrossRef]

36. Doebelin, N.; Kleeberg, R. Profex: A graphical user interface for the Rietveld refinement program BGMN. J. Appl. Crystallogr. 2015, 48, 1573-1580. [CrossRef]

37. Bergmann, J.; Friedel, P.; Kleeberg, R. BGMN-A new fundamental parameters based Rietveld program for laboratory $\mathrm{X}$-ray sources, its use in quantitative analysis and structure investigations. CPD Newsl. 1998, 20, 5-8.

38. Parkhurst, D.L.; Appelo, C.A.J. User's guide to PHREEQC (version 2.18)-a computer program for speciation, batch-reaction, one-dimensional transport, and inverse geochemical calculations. USGS Water Resour. Investig. Rep. 2011, 99-4259. Available online: https://wwwbrr.cr.usgs.gov/projects/GWC_coupled/phreeqc/html/final. html (accessed on 27 September 2020). [CrossRef]

39. Patil, N.B.; Dweltz, N.E.; Radhakrishnan, T. X-Ray measurements of crystallinity and crystallite size in swollen and hydrolyzed cottons. Text. Res. J. 1962, 32, 460-471. [CrossRef]

40. Lee, S.Y.; Lee, C.H.; Hur, H.; Seo, J.; Lee, Y.J. Characterization of Synthesized Strontianite: Effects of Ionic Strength, Temperature, and Aging Time on Crystal Morphology and Size. J. Miner. Soc. Korea 2015, 28, 195-207. [CrossRef]

41. Cao, M.; Wu, X.; He, X.; Hu, C. Microemulsion-mediated solvothermal synthesis of $\mathrm{SrCO}_{3}$ nanostructures. Langmuir 2005, 21, 6093-6096. [CrossRef]

42. Dickens, B.; Bowen, J.S. Refinement of the crystal structure of the aragonite phase of $\mathrm{CaCO}_{3}$. J. Res. Natl. Bur. Stand. Phys. Chem. A 1971, 75, 27-32. [CrossRef]

43. Pokroy, B.; Zolotoyabko, E. Aragonite growth on single-crystal substrates displaying a threefold axis. Chem. Commun. 2005, 16, 2140-2142. [CrossRef] [PubMed]

44. Wada, N.; Yamashita, K.; Umegaki, T. Effects of carboxylic acids on calcite formation in the presence of $\mathrm{Mg}^{2+}$ ions. J. Colloid Interface Sci. 1999, 212, 357-364. [CrossRef] [PubMed]

45. Zhang, F.; Xu, H.; Konishi, H.; Roden, E.E. A relationship between d104 value and composition in the calcite-disordered dolomite solid-solution series. Am. Mineral. 2010, 95, 1650-1656. [CrossRef]

46. Fang, Y.; Xu, H. A new approach to quantify the ordering state of protodolomite using XRD, TEM, and Z-contrast imaging. J. Sediment. Res. 2019, 89, 537-551. [CrossRef]

47. Feng, J.; Lee, Y.J.; Kubicki, J.D.; Reeder, R.J.; Phillips, B.L. NMR spectroscopy of citrate in solids: Cross-polarization kinetics in weakly coupled systems. Magn. Reson. Chem. 2008, 46, 408-417. [CrossRef]

48. Tadier, S.; Rokidi, S.; Rey, C.; Combes, C.; Koutsoukos, P.G. Crystal growth of aragonite in the presence of phosphate. J. Cryst. Growth 2017, 458, 44-52. [CrossRef]

49. Chakrabarty, D.; Mahapatra, S. Aragonite crystals with unconventional morphologies. J. Mater. Chem. 1999, 9, 2953-2957. [CrossRef] 
50. Loftus, E.; Rogers, K.; Lee-Thorp, J. A simple method to establish calcite: Aragonite ratios in archaeological mollusc shells. J. Quat. Sci. 2015, 30, 731-735. [CrossRef]

51. Al Omari, M.M.H.; Rashid, I.S.; Qinna, N.A.; Jaber, A.M.; Badwan, A.A. Calcium carbonate. In Profiles of drug substances, excipients and related methodology. Acad. Press 2016, 41, 31-132.

52. Phillips, B.L.; Lee, Y.J.; Reeder, R.J. Organic coprecipitates with calcite: NMR spectroscopic evidence. Environ. Sci. Technol. 2005, 39, 4533-4539. [CrossRef] [PubMed]

53. Balmain, J.; Hannoyer, B.; Lopez, E. Fourier transform infrared spectroscopy (FTIR) and X-ray diffraction analyses of mineral and organic matrix during heating of mother of pearl (nacre) from the shell of the mollusc Pinctada maxima. J. Biomed. Mater. Res. 1999, 48, 749-754. [CrossRef]

54. Siva, T.; Muralidharan, S.; Sathiyanarayanan, S.; Manikandan, E.; Jayachandran, M. Enhanced polymer induced precipitation of polymorphous in calcium carbonate: Calcite aragonite vaterite phases. J. Inorg. Organomet. Polym. Mater. 2017, 27, 770-778. [CrossRef]

55. Tobler, D.J.; Rodriguez-Blanco, J.D.; Dideriksen, K.; Bovet, N.; Sand, K.K.; Stipp, S.L. Citrate effects on amorphous calcium carbonate (ACC) structure, stability, and crystallization. Adv. Funct. Mater. 2015, 25, 3081-3090. [CrossRef]

56. Geffroy, C.; Foissy, A.; Persello, J.; Cabane, B. Surface complexation of calcite by carboxylates in water. J. Colloid Interface Sci. 1999, 211, 45-53. [CrossRef] [PubMed]

Publisher's Note: MDPI stays neutral with regard to jurisdictional claims in published maps and institutional affiliations. 